\title{
Tensionamento discursivo em torno do movimento secundarista paulista ${ }^{1}$
}

\author{
Discursive tension around the São Paulo secondary movement
}

\begin{abstract}
Vanderlei de Castro Ezequiel - Universidade Estadual Paulista (UNESP) | Araraquara | SP | Brasil | E-mail: vander.ce@gmail
\end{abstract}

Maria Ribeiro do Valle - Universidade Estadual Paulista (UNESP) | Araraquara | SP | Brasil | E-mail: maria.valle@unesp.br

Fernanda Stella Cavicchia - Universidade Estadual Paulista (UNESP) | Araraquara | SP | Brasil | E-mail: fscavicchia@gmail.com

Resumo: O objetivo deste trabalho foi verificar como a imprensa organiza a argumentação entre diferentes posições-sujeito materializadas no discurso sobre o movimento estudantil. Para tanto, foram analisadas sequências discursivas extraídas de matérias jornalísticas - publicadas na editoria de educação do jornal Folha de São Paulo - sobre as ocupações de escolas realizadas pelos estudantes secundaristas paulistas em 2015. No corpus foram identificadas duas designações diferentes e opostas: invasão e ocupação, que indicam o tensionamento discursivo em torno do movimento secundarista e, num sentido lato, como as manifestações da questão social são abordadas. Constatou-se que a designação invasão, que remete à posição-sujeito do governo estadual, apoiase no direito à posse/administração do estabelecimento educacional, enquanto a designação ocupação, que remete à posição-sujeito dos estudantes secundaristas, apoia-se no direito ao ensino público.

Palavras-chave: Questão social. Movimento estudantil. Imprensa. Invasão. Ocupação.

Abstract: The objective of this work was to verify how the press organizes the argument between different subject positions materialized in the discourse about the student movement. To do so, we analyzed discursive sequences extracted from journalistic material - published in the education editor of the newspaper Folha de São Paulo - on the occupations of schools carried out by high school students in São Paulo in 2015. In the corpus two different and opposing designations were identified: invasion and occupation, which indicate the discursive tensioning around the secondary movement and, in a broad sense, how the manifestations of the social question are approached. It was found that the name invasion, which refers to the subject position of the state government, relies on the right to possession / administration of the educational establishment, while the designation occupation, which refers to the subject position of the secondary students, relies on the right to public education.

Keywords: Social issue. Student movement. Press. Invasion. Occupation.

1 Trabalho apresentado na DT 7 - Comunicação, Espaço e Cidadania do XXIV Congresso de Ciências da Comunicação na Região Sudeste, realizado de 3 a 5 de junho de 2019.

- Recebido em 09 de maio de 2019 • Aprovado em 29 de maio de 2019 • e-ISSN: 2177-5788

DOI: https://doi.org/10.22484/2177-5788.2019v45n1p107-128

Copyright @ 2019. Conteúdo de acesso aberto, distribuído sob os termos da Licença Internaonal da CreativeCommons - CC BY-NC-SA - Atribuição Não Comercial (https://br.creativecommons.org/licencas/) Permite distribuição e reprodução, desde que atribuam os devido créditos à publicação, ao autor(es) e que licenciem as novas criações sob termos idênticos. 


\section{Introdução}

No dia 23 de setembro de 2015, o jornal Folha de S. Paulo publicou uma reportagem cuja manchete surpreendeu a comunidade escolar da rede pública paulista: "SP vai transferir mais de 1 milhão de alunos para dividir escolas por séries" (MONTEIRO, 2015). Herman Voorwald, então secretário da educação do Estado de São Paulo, anunciava nessa reportagem o projeto chamado "Reorganização Escolar". A notícia teve repercussão imediata. Muitos estudantes, professores e pais, segundo Campos, Medeiros e Ribeiro (2016), foram às ruas protestar, realizaram manifestações em espaços públicos e mobilizações nas redes sociais. Apesar de toda mobilização, o governo paulista manteve o projeto e os estudantes passaram a ocupar as escolas que seriam reorganizadas ou fechadas. As ocupações foram num crescente até atingir um ápice de mais de 200 escolas ocupadas no mês seguinte, conforme Melito (2016). Com o início das ocupações - em 09 de novembro -, o governo paulista aumentou a repressão contra o movimento estudantil: escolas cercadas pela Polícia Militar, impedindo o acesso de apoiadores aos alunos da ocupação; ameaças de expulsão dos alunos que aderissem à ocupação; truculência contra os manifestantes - inclusive menores de idade - no entorno das escolas com bombas e balas de borracha; ameaças de policiais aos secundaristas, pais e professores; detenções ilegais e tortura de alunos. Assim, a repressão contra os secundaristas, guardando as devidas proporções em relação aos acontecimentos de 1968, conforme Valle (2016), indica que na disputa entre governo e movimento estudantil o diálogo continua sendo a violência. Dessa forma, considerando que a maioria dos estudantes do ensino público paulista é oriunda das classes sociais mais pobres, Ezequiel (2005) afirma: "Evoca-se o passado quando a pobreza era concebida como caso de polícia, ao invés de ser objeto da ação do Estado no atendimento às necessidades básicas da classe trabalhadora" (p. 72).

Percebe-se, diante dessas preocupações, principalmente em relação ao direito social da educação e ao contexto social dentro da escola e seu entorno, a importância de se pesquisar as expressões da questão social no contexto da escola pública. Como afirmam Catini e Mello (2016, p. 1187), "condições degradadas de escolarização da rede pública paulista têm demonstrado que, do ponto de vista da gestão, o simples acesso à escola tornou-se sinônimo de direito à educação". De mesma forma, Andrade (2017) lembra que a escola não está isolada do contexto social em que se insere. Nas palavras de Andrade (2017, p. 30): 


\begin{abstract}
A escola apresenta inúmeras questões que ultrapassam os limites da formação pedagógica e escolar, já que se trata de um espaço múltiplo que a cada dia se transforma a partir da realidade societária. Certamente expressões da questão social estão presentes na família, na comunidade e nas relações, e acabam sendo levadas e vivenciadas também no espaço escolar, uma vez que os sujeitos não se distanciam do que vivem a partir do momento em que frequentam a escola.
\end{abstract}

Neste trabalho, pretende-se analisar o discurso sobre os secundaristas paulistas e não o discurso dos secundaristas. Assim, os discursos sobre são discursos intermediários, aqueles que ao falarem sobre um discurso se situam entre este e o interlocutor, qualquer que seja ele. Dessa forma, entende-se que o discurso jornalístico funciona como uma modalidade de discurso sobre. Especificamente, este trabalho vai examinar duas diferentes designações que remetem à luta pelo direito à escola pública: ocupação e invasão. Para realizar a análise, serão investigadas sequências discursivas recortadas de matérias jornalísticas, publicadas na editoria de educação do jornal Folha de São Paulo (doravante chamado FSP).

\title{
2 Questão Social
}

A expressão "questão social", de modo geral, começou a ser utilizada na terceira década do século XIX, e surgiu como consequência dos impactos causados pela primeira onda industrializante na Europa Ocidental. Dessa forma, entende-se que a questão social é um conjunto de problemáticas sociais, políticas e econômicas gerado pelo surgimento da classe operária dentro da sociedade capitalista. Importante ressaltar que sua origem, ligada ao continente europeu, refere-se ao processo de desenvolvimento do próprio capitalismo.

No Brasil, a noção de pobreza é ampla e ambígua, além de supor gradações. A pluralidade de situações que comporta desafia estudiosos e sociólogos e estimula a apreensão de uma concepção relativa. De maneira geral, a pobreza é medida com auxílio de indicadores de renda - tendo por base o salário mínimo -, condição de emprego e usufruto de recursos sociais que interferem na determinação do padrão de vida: moradia, saúde, educação, transporte, entre outros. Mesmo possuindo critérios heterogêneos, marcados por uma visão economicista, existe um consenso de que pobres são aqueles que não têm acesso a um mínimo de bens e recursos, seja em situação permanente ou temporária, sendo, por isso, considerados excluídos da riqueza socialmente produzida. Assim, pobres são os desempregados ou subempregados; os que estão incluídos nas faixas mais baixas de renda; aqueles que estão privados dos meios de prover a própria subsistência e que, por isso, não sobrevivem sem ajuda. Yazbek (1993) entende que a experiência da pobreza "é ainda a experiência da desqualificação dos pobres por suas crenças, seu modo de expressar-se e seu comportamento social, sinais das 'qualidades negativas' e indesejáveis que Ihes são conferidas por sua procedência de classe" (YAZBEK, 1993, p. 62). 
Nesse contexto, as desigualdades sociais não são reduzidas, ao contrário, se agravam. Conforme Ezequiel (2015, p. 96):

Vários itens da questão social atravessaram a história do Brasil: a luta pela terra, o direito de greve, as garantias de emprego, o acesso à saúde, educação, alimentação e habitação, as reivindicações do movimento negro, o problema indígena.

Dessa forma, perpetuam-se as condições para existência da nãocidadania que, segundo Telles (2006, p. 95), é o lugar no qual "a pobreza vira 'carência', a justiça se transforma em caridade e os direitos em ajuda, a que o indivíduo tem acesso não por sua condição de cidadania, mas pela prova de que dela está excluído".

Atualmente, são amplamente conhecidas as condições de precariedade de grande parte da oferta de ensino público no Brasil, sempre carente de maiores investimentos e priorização. Projetos governamentais ancorados na ideologia neoliberal de mercantilização e privatização da educação vão de encontro à necessidade de uma política educacional implementada para superar as discriminações e reduzir as desigualdades.

Embora a escola não seja a origem dos problemas, ela os reflete. É deste lugar chamado escola que se tem uma compreensão do problema da educação pública. Para Peregrino (2006, p. 12):

É ali, quando tudo começa, que percebemos as interdições, degradações e injustiças que passarão a demarcar os contornos dessas vidas em seu início. Assim, se a escola não produz as condições que delimitarão daí por diante as vidas "que começam", ela, com certeza, as reproduz. A escola, portanto não é o início do ciclo onde tudo começa, mas demarca o espaço de conservação e de "perpetuação" do movimento: quando tudo re-começa.

\section{Análise de Discurso}

A Análise de Discurso² tem como propósito "a compreensão de como um objeto simbólico produz sentidos, como ele está investido de significância para e por sujeitos". Essa compreensão, ainda segundo a autora, "implica em explicitar como o texto organiza os gestos de interpretação que relacionam sujeito e sentido. Produzem-se assim novas práticas de leitura" (ORLANDI, 2010, p. 26-27). Para a autora, os dizeres não são apenas mensagens passíveis de decodificação, mas efeitos de sentidos produzidos em condições determinadas, e que deixam vestígios no modo como se diz,

São pistas que ele aprende a seguir para compreender os sentidos aí produzidos, pondo em relação o dizer com sua exterioridade, suas

\footnotetext{
2 Para simplificar a leitura, daqui em diante Análise de Discurso passa a ser denominada por AD.
} 
condições de produção. Esses sentidos têm a ver com o que é dito ali, mas também em outros lugares, assim como com o que não é dito, e com o que poderia ser dito e não foi. Desse modo, as margens do dizer, do texto, também fazem parte dele (ORLANDI, 2010, p. 30).

Entretanto, não existem sentidos "literais" arquivados em algum compartimento do cérebro e que "aprendemos" a utilizar. A constituição dos sentidos e dos sujeitos se dá em processos, nos quais coexistem os jogos simbólicos - que não temos o controle - e o equívoco, por meio do trabalho da ideologia e do inconsciente. Dessa maneira, pode-se afirmar que as visões de mundo se materializam na linguagem em suas diferentes manifestações: a verbal, a visual, a gestual, etc. A maneira de pensar o mundo, numa dada época, subordina-se aos temas e figuras estabelecidos por essas visões de mundo. Assim, a maior parte dos discursos produzidos numa formação social concreta repete esses temas e figuras. Com relação à Formação Discursiva (também representada por FD), Fiorin (1988, p. 14), afirma que:

Temos, então, que considerar a formação ideológica como uma visão de mundo, ou seja, o ponto de vista de uma classe presente numa determinada formação social, e a formação discursiva como o conjunto de temas e figuras que materializam uma dada formação ideológica.

Dessa forma, entende-se que o texto é também um lugar de manipulação consciente, onde o sujeito falante organiza recursos de expressão para veicular, da melhor maneira possível, determinados discursos. O sujeito de uma dada formação social tem na FD a matéria-prima para elaborar seus discursos. No geral, ele reproduz em seus discursos as figuras e os temas presentes nos discursos dominantes de uma dada época, num determinado espaço geográfico. Entende-se, então, que "O enunciador real sempre vocaliza as formações ideológicas existentes na formação social em que vive" (FIORIN, 1988, p. 16).

Embora seja depositário de várias FDs presentes numa formação social concreta - dividida em classes sociais distintas - o enunciador, sendo um ser social, geralmente é suporte apenas da FD dominante, que materializa a formação ideológica dominante.

Outra noção importante no âmbito da análise do discurso é a de Condições de Produção do discurso. As Condições de Produção (doravante CP) trazem para o discurso os lugares sociais e suas representações, e também as relações de força e as relações de mundo da sociedade, independente da dimensão contextual - estrita ou ampla. As CP "constituem a instância verbal de produção do discurso, o contexto histórico-social, os interlocutores, o lugar de onde falam e a imagem que fazem de si, do outro e do referente" (BRANDÃO, 2004, p. 105).

Conforme Orlandi (2010), o sentido estrito das CP refere-se ao contexto imediato da enunciação, enquanto o sentido amplo inclui os contextos sóciohistórico e ideológico. As CP em sentido amplo abrangem, além do contexto 
sócio-histórico, também do imaginário produzido pelas instituições, sobre o já-dito, sobre a memória. Para Orlandi (2010), essa "memória do dizer" refere-se ao interdiscurso, ou seja, ao exterior constitutivo do discurso.

\begin{abstract}
O interdiscurso é todo o conjunto de formulações feitas e já esquecidas que determinam o que dizemos. Para que minhas palavras tenham sentido é preciso que elas já façam sentido. E isto é efeito do interdiscurso: é preciso que o que foi dito por um sujeito específico, em um momento particular se apague na memória para que, passando para o "anonimato", possa fazer sentido em "minhas" palavras (ORLANDI, 2010, p. 33-34).
\end{abstract}

Responsável pelos sentidos que provêm de outro lugar, esse exterior constitutivo revela a necessidade dos movimentos parafrásticos e polissêmicos para a constituição dos sentidos. Entende a autora que o sentido surge a partir de deslocamentos do já-dito, em outras palavras, da memória do dizer. Sobre o interdiscurso, Orlandi (2010, p. 32-33) relaciona-o a um eixo de constituição, "um eixo vertical onde teríamos todos os dizeres já ditos - e esquecidos - em uma estratificação de enunciados que, em seu conjunto, representa o dizível". Já o eixo horizontal - intradiscurso ${ }^{3}$ - refere-se à formulação, isto é, "aquilo que estamos dizendo naquele momento dado, em condições dadas" (ORLANDI, 2010, p. 33). Dessa forma, toda enunciação encontra-se no cruzamento dos dois eixos: o da memória (constituição) e o da atualização do já-dito (formulação).

\footnotetext{
${ }^{3}$ Intradiscurso "opõe-se ao interdiscurso como as relações entre os constituintes do discurso opõem-se às relações desse discurso com outros" (MAINGUENEAU, 2000, p. 90).
} 


\section{Designações Antagônicas}

Neste trabalho pretende-se verificar como a imprensa organiza a argumentação entre duas diferentes posições-sujeito ${ }^{4}$. Para composição do corpus, foram analisadas todas as matérias publicadas na editoria de educação no período de 23 de setembro a 05 de dezembro de 2015 . Dentre as matérias publicadas no período, foram selecionadas aquelas que continham os termos: "estudantes" e "reorganização", totalizando 120 matérias. Destas, foram selecionados os títulos das matérias jornalísticas publicadas entre 10 de novembro e 5 de dezembro, período que compreendeu as ocupações de escolas $^{5}$, num total de 39 matérias. Desse total, 19 matérias explicitavam a designação "invasão" no título e 20 matérias a designação "ocupação". Para composição dos recortes utilizados neste texto, orienta-se pela proposta de Orlandi (2010), que postula que essa delimitação não segue critérios empíricos, mas teóricos ${ }^{6}$.

As duas designações diferentes e opostas: invasão e ocupação remetem ao posicionamento da imprensa - sujeito discursivo num lugar-fronteira sobre o movimento dos estudantes secundaristas paulistas.

Para examinar como se estrutura a argumentação no discurso da mídia sobre o movimento dos estudantes será mobilizada a noção de FD, tal como foi formulada por Pêcheux et al. (1990, p. 102 apud MAINGUENEAU, 2000, p. 68) - aquilo que pode e deve ser dito em um discurso. Também será trabalhada a noção de sujeitos historicamente determinados, pois nesse tipo de disputa estão materializadas posições-sujeito antagônicas.

\footnotetext{
4"Pensando-se a subjetividade, podemos então observar os sentidos possíveis que estão em jogo em uma posição-sujeito dada. Isso porque, como sabemos, o sujeito, na análise de discurso, é posição entre outras, subjetivando-se na medida mesmo em que se projeta de sua situação (lugar) no mundo para sua posição no discurso. Essa projeção-material transforma a situação social (empírica) em posição-sujeito (discursiva). Vale lembrar que sujeito e sentido se constituem ao mesmo tempo, na articulação da língua com a história, em que entram o imaginário e a ideologia. Se, na Psicanálise temos a afirmação de que o inconsciente é estruturado como linguagem, na Análise de Discurso considera-se que o discurso materializa a ideologia, constituindo-se no lugar teórico em que se pode observar a relação da língua com a ideologia" (ORLANDI, 1999, p. 11).

5 No dia 9 de novembro de 2015, a Escola Estadual Diadema, na Grande São Paulo, foi ocupada pelos alunos. No dia seguinte, a Escola Estadual Fernão Dias Paes, situada no bairro de Pinheiros, em São Paulo também foi ocupada. Na sequência outras escolas foram alvo dos estudantes, atingindo um ápice de mais de 200 escolas ocupadas no mês seguinte.

${ }^{6}$ Sabe-se que a escolha de um objeto a ser analisado, utilizando-se a fundamentação teórica da Análise de Discurso, não pode ser aleatória. Dessa forma, os recortes têm que vir com os objetivos propostos pelo analista. Conforme Orlandi (2010), o objeto discursivo não é dado, ele supõe um trabalho inicial do analista. Num primeiro momento de análise, é preciso converter o corpus bruto, empírico em um objeto teórico.
} 


\section{A Designação Invasão}

Primeiramente, serão apresentadas as 19 sequências discursivas títulos das matérias jornalísticas - com a designação "invasão" e suas respectivas datas de publicação no jornal FSP, conforme consta no Quadro 1.

Quadro 1 - Designação "invasão" (elaborado pelos autores)

\begin{tabular}{|c|c|}
\hline Publicação & Título da matéria \\
\hline $10 / 11 / 2015$ & Estudantes invadem e trancam escola em ato contra fechamentos em SP \\
\hline $11 / 11 / 2015$ & Estudantes mantêm invasão de escola estadual em SP \\
\hline $11 / 11 / 2015$ & Pai tenta tirar filha de escola invadida e manifestantes pedem 'Fica, Fabíola!' \\
\hline $12 / 11 / 2015$ & Aluno 'linha de frente' do Passe Livre é porta-voz de invasão em escola de SP \\
\hline $12 / 11 / 2015$ & Alunos de invasão e governo terão audiência de conciliação, diz defensora \\
\hline $12 / 11 / 2015$ & Alunos invadem escola na zona leste de SP que será fechada por Alckmin \\
\hline $12 / 11 / 2015$ & Pais aderem a ato de alunos em SP, mas pedem invasão 'sem baderna' \\
\hline $12 / 11 / 2015$ & Sobe para cinco o número de escolas estaduais invadidas na Grande SP \\
\hline $13 / 11 / 2015$ & Justiça revoga reintegração de posse de escola invadida; alunos comemoram \\
\hline $13 / 11 / 2015$ & Sobe para 8 o número de escolas estaduais invadidas na Grande SP \\
\hline $14 / 11 / 2015$ & MTST invade três escolas estaduais em Protesto contra 'reorganização' \\
\hline $15 / 11 / 2015$ & Pais se revezam em vigília diante de escola invadida em SP \\
\hline $15 / 11 / 2015$ & Repórter da Folha passa quatro dias em escola invadida e relata rotina \\
\hline $17 / 11 / 2015$ & Estudantes invadem escolas estaduais em Campinas e Jundiaí \\
\hline $17 / 11 / 2015$ & Invasão de 25 escolas estaduais atinge ao menos 26 mil alunos em SP \\
\hline $17 / 11 / 2015$ & Temos de pedir a reintegração de escolas invadidas, diz secretário de Alckmin \\
\hline $22 / 11 / 2015$ & Às vésperas de dia decisivo, escola invadida em Pinheiros faz mini festival \\
\hline $23 / 11 / 2015$ & Governo paulista cancela prova estadual em escolas invadidas \\
\hline $24 / 11 / 2015$ & $\begin{array}{l}\text { Só diálogo supera essa situação', diz Mercadante sobre invasão de escolas em } \\
\text { SP }\end{array}$ \\
\hline
\end{tabular}

Fonte: Jornal Folha de S. Paulo - versão digital. 
Logo no início das ocupações, identificou-se uma primeira posiçãosujeito envolvida nesse processo de designação: a do Governo do Estado de São Paulo. Trata-se, então, de designar de "invasão" a permanência dos estudantes secundaristas no ambiente escolar por tempo indeterminado.

A utilização da designação "invasores", ao se referir aos estudantes, com todos os efeitos de sentido que dela provêm, está garantida por um discurso que imobiliza a noção de direito à educação, desconsiderando os estudantes como interlocutores no processo de organização da rede de ensino público. Esse posicionamento retira a demanda da esfera jurídica e administrativa e lança-a na esfera policial. Afinal, o invasor precisa ser retirado, se necessário à força, do imóvel invadido.

Dessa forma, as sequências discursivas com a designação "invasão" representam o discurso da imprensa como negação do movimento estudantil. Este discurso está inscrito na FD conservadora que salienta o direito do governo estadual em organizar a rede de ensino e administrar o patrimônio público, neste caso, os estabelecimentos de ensino. Além disso, não considera o direito dos estudantes em participar das decisões sobre o destino das escolas. Por outro lado, este discurso deixa na sombra o direito à educação pública, gratuita e de qualidade, que implica a oferta de vagas em condições adequadas às necessidades dos estudantes, principalmente, em relação à distância entre a escola e a residência do aluno. Não se pode negar que a imprensa dá visibilidade ao litígio, porém, ao fazê-lo, o faz de um lugar ${ }^{7}$ identificado com o discurso do governo. Neste sentido, não é possível alegar neutralidade da imprensa.

\footnotetext{
${ }^{7}$ Conforme Orlandi (2010, p. 39-40), "podemos dizer que o lugar a partir do qual fala o sujeito é constitutivo do que ele diz [...] Como nossa sociedade é constituída por relações hierarquizadas, relações de força, sustentadas no poder desses diferentes lugares, que se fazem valer na 'comunicação'".
} 


\section{A Designação Ocupação}

Em seguida, serão apresentadas as 20 sequências discursivas - títulos das matérias jornalísticas - com a designação "ocupação" e suas respectivas datas de publicação no jornal FSP.

Quadro 2 - Designação "ocupação" (elaborado pelos autores)

\begin{tabular}{|c|c|}
\hline Publicação & Título da matéria \\
\hline $19 / 11 / 2015$ & $\begin{array}{l}\text { Alunos fazem contraproposta à oferta de governo para desocupação de } \\
\text { escolas }\end{array}$ \\
\hline $19 / 11 / 2015$ & Gestão Alckmin faz proposta para alunos desocuparem escolas \\
\hline $21 / 11 / 2015$ & Sobe para 74, número de escolas ocupadas em SP \\
\hline $24 / 11 / 2015$ & Estudantes ocupam escola estadual na zona leste de São Paulo \\
\hline $24 / 11 / 2015$ & Ocupação de escolas em SP sobe $40 \%$ em dia de exame e atinge 151 unidades \\
\hline $25 / 11 / 2015$ & Inspirado no Chile, manual orientou ocupação de escolas por alunos em SP \\
\hline $26 / 11 / 2015$ & Com medo de ocupação, Fuvest tira prova de todas as escolas estaduais \\
\hline $26 / 11 / 2015$ & Famílias se articulam para reverter ocupação de escolas em SP \\
\hline $26 / 11 / 2015$ & Por ocupações, Fuvest muda locais de prova e tira escolas estaduais da lista \\
\hline $26 / 11 / 2015$ & Sindicato deve ir à Justiça contra corte de bônus a docente de escola ocupada \\
\hline $27 / 11 / 2015$ & Agenda cultural em colégios ocupados inclui circo, debate e até cursinho \\
\hline $27 / 11 / 2015$ & Com ocupações, prova nas escolas estaduais de SP tem sua pior adesão \\
\hline $28 / 11 / 2015$ & Governo Alckmin infla balanço de desocupações de escolas em SP \\
\hline $30 / 11 / 2015$ & Alunos a favor de ocupações de escolas liberam av. Faria Lima após 3 horas \\
\hline $30 / 11 / 2015$ & Escolas ocupadas em Paraisópolis têm tumulto e ofensas a alunos \\
\hline $30 / 11 / 2015$ & Governo fará visitas a escolas ocupadas para tentar frear Protestos \\
\hline $01 / 12 / 2015$ & Alunos liberam ponte João Dias e ocupam ruas da zona sul da cidade \\
\hline $03 / 12 / 2015$ & Governo de SP aposta em desgaste de ocupações, e alunos radicalizam \\
\hline $04 / 12 / 2015$ & Após recuo de Alckmin, estudantes decidem manter ocupação em escolas \\
\hline $05 / 12 / 2015$ & Segunda escola ocupada é depredada em Osasco, na Grande SP \\
\hline
\end{tabular}

Fonte: Jornal Folha de S. Paulo - versão digital. 
Em contrapartida, os estudantes secundaristas, cansados de aguardar pela abertura de diálogo com o governo estadual paulista, e almejando o cancelamento do projeto da reorganização, decidiram aumentar a pressão sobre o governo paulista. Para tanto, identificaram as escolas que seriam fechadas ou afetadas diretamente pelo projeto de reorganização, e passaram a ocupar esses prédios. Seu propósito, expresso pelo lema "ocupar e resistir" é o enfrentamento direto com o governo, forçando-o a reconhecer suas demandas. Dessa forma, a posição-sujeito em que os estudantes estão inscritos designa sua prática de ocupação.

Ou seja, trata-se de uma reafirmação de direito à educação, amparado em uma ética social do discurso jurídico sobre o direito à escola pública. Nesse sentido, a Constituição da República Federativa do Brasil de 1988 prevê, em seu artigo 205, que a educação é um direito social que deve ser provido pelo Estado:

A educação, direito de todos e dever do Estado e da família, será promovida e incentivada com a colaboração da sociedade, visando ao pleno desenvolvimento da pessoa, seu preparo para o exercício da cidadania e sua qualificação para o trabalho (BRASIL, 2000, p. 117).

Assim, diante do contínuo processo de degradação do ensino estatal, das medidas governamentais com fins privatizantes do ensino e do aprofundamento da redução dos gastos sociais, as manifestações dos estudantes secundaristas impuseram uma contundente defesa do ensino público gratuito, estabelecendo uma crítica à forma escolar inserida no capitalismo.

A designação "ocupação" é representativa do processo de contestação dos estudantes em relação às decisões governamentais sobre educação. $\mathrm{Na}$ FD em que os estudantes se inscrevem, as escolas são ocupadas, e é lícito fazerem-se ocupações, pois através das escolas se concretiza o acesso ao ensino público gratuito. Trata-se de uma estratégia dos alunos (ocupar) para forçar o governo a dialogar sobre os rumos do ensino público especificamente sobre o fechamento de escolas -, amparada numa ética social sobre o direito à educação. Dessa forma, consideram legítimo questionar e impor resistência às ações governamentais entendidas como prejudiciais ao acesso à educação pública. Assim procedendo, os estudantes promovem uma discussão que mobiliza fortemente a questão de direitos, além de amplificar a divulgação das ações do movimento estudantil na mídia. 


\title{
7 Efeitos de Sentido
}

Os títulos das matérias publicadas no jornal FSP mostram a presença de dois discursos opostos, pertencentes a dois sujeitos históricos e ideologicamente antagônicos: aquele que desde a organização da burocracia estatal brasileira opera como gerenciador dos recursos públicos; e aquele sujeito de direito, que surge do não-lugar, dentre os que vivem nas bordas da exclusão: os estudantes pobres usuários da escola pública ${ }^{8}$. O encontro desses dois discursos se dá em um lugar-fronteira que, por vezes, se materializa no discurso da mídia. Dentro desse discurso, a interlocução é atravessada pelo dissenso, pelo estranhamento, pelo desentendimento e pelas interpretações conflitantes de ambas as partes em litígio.

No embate entre governo e secundaristas, o primeiro não reconhece a existência do segundo como seu interlocutor e, dessa forma, não o reconhece como qualificado para o diálogo. No limite, não há possibilidade de interlocução. Decorre deste desentendimento o modo como se organiza o funcionamento da argumentação no discurso de grande parte da mídia sobre o movimento estudantil.

\begin{abstract}
Os secundaristas, por exemplo, constroem em seu discurso, com a declaração de que o governo lhes nega diálogo, uma imagem de estado autoritário que os proíbe e os exclui da construção de um projeto educacional que os afeta diretamente. No sentido contrário, negando o discurso dos estudantes, o governo tenta se afastar da imagem de autoritarismo, deslocando os sentidos estabelecidos pelos secundaristas, em torno da palavra diálogo, para uma imagem conciliadora e colaborativa [...] Assim, a palavra diálogo não corresponde aos sentidos de conciliação e colaboração, ela corresponde a um discurso sobre conciliação e colaboração. Em outras palavras, o que importa para o governo não é o diálogo em si, mas um discurso sobre a existência do diálogo (GALELLI; BEDÊ, 2017, p. 293).
\end{abstract}

No corpus analisado, os dois discursos em tensão: o discurso governamental e o discurso dos estudantes secundaristas são discursos produzidos de lugares políticos diferentes, configurando um espaço discursivo marcado pelo confronto de FD antagônicas. Portanto, na ausência de uma cena discursiva de interlocução, é através das narrativas da imprensa que a maioria toma conhecimento dos argumentos destas diferentes subjetividades sociais.

As manifestações dos estudantes impuseram a presença - momentânea - de um novo sujeito político no espaço público paulista, o qual passa a demandar em nome de uma fração dos excluídos - estudantes pobres de

8 "O movimento de ocupações de escolas paulistas se demonstrou uma importantíssima escola de luta - não apenas para seus jovens protagonistas -, cuja maior lição é a de que as lutas imediatas em defesa de uma educação de qualidade para os pobres podem e devem se dar como um ensaio de insurreição popular, avançando contra a burguesia na disputa pelo direito ao conhecimento, à ciência e ao poder" (BRITO, 2017, p. 327). 
escolas públicas. Por outro lado, o posicionamento inflexível do governo paulista, recusando-se a debater o projeto de reorganização com os estudantes, situa-o como sujeito político portador da fala oficial, representante da vontade da maioria da população.

O confronto expõe dois sujeitos antagônicos: aquele que desde sempre teve direito de falar sobre a coisa pública, ou melhor, sobre a educação pública, portanto um sujeito de direito; e o que surge do não-lugar, emerge dentre os excluídos, o movimento estudantil secundarista paulista que toma a palavra para reivindicar o direito à educação. Dessa forma, tais sujeitos políticos só podem instituir-se em FD antagônicas, encontrando-se somente no lugar-fronteira ${ }^{9}$ : na mídia. Fora desse lugar-fronteira não há possibilidade de interlocução e, no interior dele, a interlocução é atravessada pelo dissenso e pelo não reconhecimento das interpretações de ambas as partes em litígio. E quando não há o reconhecimento do outro, a cena discursiva de interlocução não se constitui.

Neste sentido, o escritor, educador e ativista do movimento de saraus de poetas da periferia, Allan da Rosa, que apoiou o movimento secundarista na capital paulista, esclarece:

\begin{abstract}
Eles querem mais diálogo na condução da política pública de educação e na tomada de decisões internas de cada escola. Têm fome de didáticas e pedagogias que superem o tédio. Estudantes dizem não aguentar mais que toda aula seja o mesmo blá-blá-blá de um professor falando sozinho em frente à lousa sem mostrar o encanto da matéria e do conhecimento que trata. Estudantes desejam que, da cozinha ao pátio, dos banheiros aos jardins, a escola toda seja um espaço de ampliação e partilha de conhecimento, de criação e reflexão sobre sua vida e nosso cotidiano, história e sociedade. Nas periferias há uma efervescência cultural que tanto luta e anuncia temas indigestos aos poderosos quanto já apresenta também a contradição entre a posição de currais eleitorais e o extremo ceticismo com movimentos sociais, em geral esculhambados ou invisibilizados pela mídia graúda. Os estudantes de 2015 traçaram elos com lideranças comunitárias e pais e mães de alunos que encamparam a luta de seus filhos (NAVARRO; BRASILINO, 2016).
\end{abstract}

Em decorrência dessa ausência de uma cena de legítima interlocução ausência de diálogo com as autoridades -, os estudantes impuseram uma estratégia política que visou conquistar seu acesso à escola. Para tanto, mobilizaram práticas políticas, que desencadearam, por sua vez, uma prática discursiva que pôs a questão da educação pública em evidência no discurso social paulista, além de questionar a eficácia da ação governamental e sua vontade política de efetivamente garantir um ensino de qualidade.

9 O lugar-fronteira corresponde a uma zona de "interincompreensão constitutiva" (MAINGUENEAU, 1989, p. 119-120). 
No discurso dos estudantes, a permanência por tempo indeterminado no ambiente escolar é designada de ocupação, enquanto no discurso das autoridades governamentais, a prática dos estudantes é designada por invasão. Essa dupla designação poderia, num primeiro momento, ser considerada pelo viés da sinonímia, pois tanto ocupação quanto invasão remetem, referencialmente, ao ato praticado pelos estudantes: permanecer no interior do estabelecimento de ensino por tempo indeterminado. Entretanto, não é este o caso.

A designação "ocupação" tem como referente o direito à escola pública. Já a designação "invasão" constrói como referente a administração da escola pública. A primeira, por tratar do direito à educação, trabalha o sentido social de uma escola que, por correr o risco de ser fechada, deve ser protegida para que aqueles que desejam/necessitam estudar possam contar com o espaço físico para realização desse direito. Além disso, remete à ideia de ação pacífica exercida sobre o patrimônio público (de todos). A segunda, por possuir um administrador (o governo), põe em relevo o sentido gerencial de otimização de recursos financeiros e melhor aproveitamento dos prédios destinados à educação. Também aponta para o desrespeito à lei e a ilegalidade daqueles que adotam a prática da invasão e violam o patrimônio público sob a administração estatal.

Para Catini e Mello (2016), a escola, na atual conjuntura brasileira, tornou-se um fim em si mesmo e tende a esvaziar-se de conteúdo:

[...] fazendo com que prevaleça a forma sobre a formação, um fetichismo educativo em sentido rigoroso, em que as relações sociais são coisificadas e presididas pelas formas, que se subjetivam. Esse processo assume determinações particularmente perversas no que tange à educação das camadas mais pauperizadas da população, que por vezes são premidas a passar anos e anos nas escolas, onde se socializam, mas não necessariamente têm acesso aos conteúdos escolares que, em tese, legitimam o processo de escolarização (CATINI, 2013 apud CATINI; MELLO, 2016, p. 1187).

Constata-se que estas duas designações representam duas posiçõessujeito opostas, que se inscrevem em FDs antagônicas, permitindo dois discursos que se excluem mutuamente, construindo aí um lugar-fronteira entre esses saberes e dizeres sobre a educação. Essa disputa de sentidos faz emergir uma discussão sobre os lugares políticos no Brasil.

Cabe dizer que as duas designações coexistem na mesma língua. Porém, o uso de uma ou de outra utiliza discursivamente sentidos diferentes que remetem a processos discursivos também diferentes, e que se encontram em situação de ocorrência concomitante no espaço discursivo desenhado pela imprensa em seu discurso sobre o movimento estudantil. Essas duas posiçõessujeito, lembra Indursky (2003) não são utilizadas concomitantemente no mesmo enunciado. Conforme Indursky (2003, p. 61): 
Quando tais redes discursivas são acionadas, elas trazem os saberes de uma ou outra rede discursiva de formulação, antagônicos entre si e inscritos em Formações Discursivas em confronto, que apontam para as relações de tensão que existem atualmente na cena discursiva brasileira.

Consequentemente, somente em um lugar-fronteira - como o discurso da imprensa - é possível mobilizar, ao mesmo tempo e de forma tão intensa, as condições de produção de duas FDs em disputa, permitindo o encontro de duas subjetividades históricas distintas, de saberes diversos.

\section{A Posição-Sujeito da Imprensa}

O conhecimento da realidade, na sociedade contemporânea, constituise preferencialmente a partir da recepção das formas simbólicas veiculadas pela mídia. A prevalência das tecnologias de comunicação e a facilidade de acesso à informação afetam a vida no espaço público, conferindo cada vez mais importância à mídia.

A mídia deve ser analisada nesta diversidade de possibilidades: informando e formando a opinião pública. As representações construídas pela mídia tornaram-se fundamentais nas experiências individuais e sociais na contemporaneidade (CHAIA, 2004, p. 23).

Entretanto, o significado das informações que circulam através da mídia necessita ser avaliado, pois como afirma Chaia (2004), se por um lado a presença intensa da mídia na vida das pessoas favorece o acúmulo de informações, ampliando as possibilidades simbólicas dos indivíduos e favorecendo a reflexão, por outro, "pode trazer consequências negativas ao introduzir mensagens ideológicas" (p. 22-23).

A imprensa, ator privilegiado da mídia na produção e circulação de informação, seleciona e prioriza notícias seguindo critérios dos chamados gatekeepers (porteiros), constituindo uma "praça pública seletiva" (SILVA, 2002, p. 52). Repórteres, editores, proprietários dos jornais, lobbies influenciam e condicionam a inclusão ou exclusão de determinadas matérias, consumando um complexo processo de elaboração. Consequentemente, o recorte que o jornalista realiza para escolher o assunto que irá trabalhar permite selecionar e construir o enfoque que deverá privilegiar em sua matéria. "A seletividade é uma condição própria da mídia, cujas escolhas sempre obedecem a critérios de noticiabilidade, audiência ou pura espetacularização" (p. 53). A seleção do que será noticiado, envolve um "processo complexo e sujeito, em todo o seu percurso, a pressões e condicionamentos políticos, ideológicos e econômicos" (p. 126). São eles: a elaboração da pauta; escolha das fontes; cortes da realidade; prioridades atribuídas; ângulos de cada matéria; forma como o real é submetido ao texto; enquadramentos; ênfases efetuadas por diagramadores e editores. Tal processo "expressa o exercício explícito do poder, assim como pode ser tomado como um sutil momento de expressão concreta da ideologia" (MOTTA, 
2002, p. 126). Além da seleção, as notícias frequentemente sofrem transformações para torna-las mais interessantes ao público: "enfatizar dramas e conflitos; personalizar as notícias apresentando pessoas concretas na representação das instituições, ideias e outras formas impessoais que por elas mesmas são difíceis de visualizar; reduzir assuntos à simples histórias com moral" (CHAIA, 2004, p. 16).

Relatar um fato consiste em "exercer suas faculdades de raciocínio para analisar o porquê e o como dos seres que se acham no mundo e dos fatos que aí se produzem" (CHARAUDEAU, 2012, p. 175). Assim, o relato é uma atividade discursiva que propõe uma visão de mundo de ordem do constativo. Pode ser descrito como sucessão de ações cuja lógica depende dos atores que implica, sendo que o mundo relatado é apenas um testemunho possível da experiência humana. Cada indivíduo pode projetar-se no mundo relatado, ou rejeitá-lo. Neste sentido, o "discurso da mídia, ao fazer sua argumentação, apaga possíveis diferenças, possíveis nuances. Em sua ótica, fica apenas uma única leitura, que é dada como a leitura" (INDURSKY, 2003, p. 62).

No campo jornalístico existem regras que determinam o que é legítimo ser falado, além disso, esse campo é atravessado por disputas originadas pela variação de posição dos agentes em relação à aceitação, ou não, das demandas mercadológicas.

As falas num jornal estão ligadas à complexa rede de interesses que existem na atividade jornalística. Quem fala num jornal, fala a partir de relações objetivas de dominação, subordinação, complementaridade ou antagonismo, ou seja, fala a partir de posições sociais diferentes, que detêm ou não os diversos capitais (AMARAL, 2005, p. 111).

\section{Tensionamento Discursivo}

A dupla designação presente nos títulos das matérias jornalísticas publicadas no jornal FSP aqui analisada sinaliza a existência de duas formassujeito antagônicas, inscritas em FDs em confronto que apontam para a disputa de sentidos instaurada na mídia. E a disputa governo-estudantes materializa-se nas páginas dos jornais, transmutando-se no tempo em decorrência do contexto conflituoso que se agudiza entre os dois lados.

Geralmente, numa disputa de discursos, a mídia identifica-se com uma das posições já postas, a favor de A ou a favor de B. No caso em análise, observa-se que o jornal FSP se identificou claramente com a posição-sujeito do governo estadual, mudando seu posicionamento posteriormente. 
Gráfico 1 - Invasão x ocupação (elaborado pelos autores).

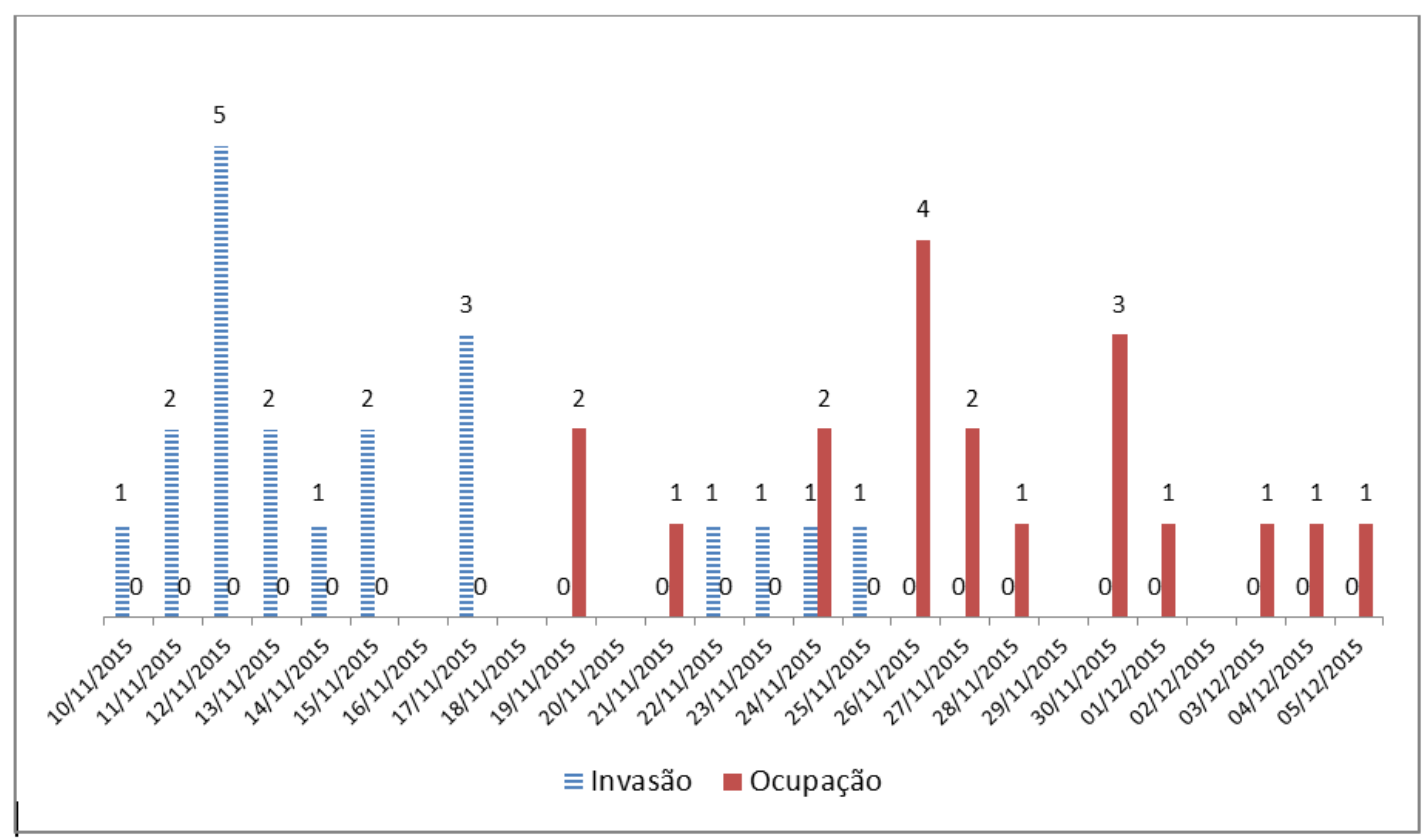

Fonte: Jornal Folha de S. Paulo - versão digital

No gráfico acima é possível identificar o número de matérias jornalísticas contendo as designações "ocupação" e "invasão", totalizadas por data de publicação. Interessante notar que até o dia 18 de novembro o jornal utilizou apenas a designação "invasão". Entre os dias 19 e 25 de novembro são publicadas matérias com títulos exibindo as duas designações. E a partir de 26 de novembro, somente a designação "ocupação" é mencionada nos títulos das matérias publicadas.

Verifica-se, a partir das sequências discursivas selecionadas, uma variação na posição-sujeito desse veículo jornalístico. No início das manifestações dos estudantes há uma indubitável identificação de sua linha editorial com a posição-sujeito do governo estadual. Neste sentido, ao dar visibilidade ao litígio social, o faz criminalizando a ação dos estudantes: invasores. Por outro lado, passados 10 dias, o jornal passa a defender a posição-sujeito dos estudantes e, consequentemente, a utilizar a designação "ocupação". Assim, enquanto no início das manifestações os estudantes eram sujeitos fora da lei, com o aumento do número de escolas ocupadas, o jornal altera sua posição e passa a considerar legítima a demanda dos estudantes, agora considerados sujeitos dentro da lei. 
No processo discursivo do discurso da mídia, à semelhança do discurso literário, são necessários diferentes enunciados, mobilizados por diferentes sujeitos sociais, para veicular argumentos de sujeitos históricos igualmente diversos. Ou seja: na mídia, para representar as diferentes vozes sociais e sua argumentação faz-se necessário mobilizar, não apenas diferentes enunciados, mas diferentes redes discursivas de formulações, que remetem a dois sujeitos históricos diferentes e em situação de litígio (INDURSKY, 2003, p. 64).

Durante o processo discursivo, não é um locutor que se faz presente, mas um sujeito historicamente determinado que, dessa maneira, diz apenas o que sua posição-sujeito lhe determina/permite dizer. Além disso, ignora/silencia os argumentos do outro sujeito histórico, desqualificando os saberes deste outro, seu antagonista ideológico.

Sobre a participação dos grandes periódicos nacionais - a Folha de São Paulo era um deles - na cobertura dos acontecimentos envolvendo o confronto entre o movimento estudantil e o governo autoritário em 1968, Valle (2016) observa a importância da imprensa na conformação da opinião pública. Conforme Valle (2016, p. 15):

\begin{abstract}
Em nenhum momento tratados como meros observadores, nem mesmo como participantes indiretos por seu poder de manipular o real e influenciar a opinião pública, estes últimos [grandes periódicos nacionais] saltam do texto como personagens "coadjuvantes" do drama em curso: tomam partidos, recebem o impacto dos acontecimentos, mudam de "olhar" e reformulam suas técnicas de intervenção, contribuindo para criar fatos políticos novos e sofrendo suas consequências.
\end{abstract}

\title{
10 Considerações Finais
}

Neste artigo foram analisadas duas designações diferentes e opostas: invasão e ocupação que remetem ao funcionamento da imprensa sobre o movimento estudantil, num sentido stricto sensu, e sobre a questão social num sentido lato sensu. Constatou-se que a designação invasão, que refere à posição-sujeito do governo estadual, apoia-se no direito à posse/administração do estabelecimento educacional, enquanto a designação ocupação, que remete à posição-sujeito dos estudantes secundaristas, apoiase no direito à educação. Essas designações mostram esse confronto de discursos, revelando a disputa de sentidos nas páginas do jornal paulista.

Os argumentos que foram materializados na FSP são antagônicos entre si e representam o importante litígio social sobre a questão da educação no Brasil contemporâneo. Sendo antagônicos, não podem ser mobilizados pelo mesmo sujeito histórico e, dessa forma, só podem encontrar-se reunidos no interdiscurso. Entendendo o interdiscurso como o lugar onde todos os sentidos são possíveis, pois neste ponto os sentidos ainda não passaram pelo crivo de nenhuma FD. 
Certamente, as práticas discursivas e não-discursivas dos estudantes secundaristas paulistas podem ser entendidas como atividades políticas, pois pautaram demandas e conferiram maior visibilidade ao movimento. Por outro lado, isso não significa fidelidade quanto aos sentidos que circularam na imprensa, mas o vigoroso sujeito político que emergiu dessa disputa adquiriu a capacidade de produzir cenas polêmicas, demandas e discursos em confronto com seu antagonista, o governo paulista.

Sabe-se que a imprensa, como produtora de informações, coloca-se como fonte geradora de sistemas de representação da realidade, utilizada para compreender a sociedade. Nesse sentido, num contexto democrático a imprensa adquire enorme poder como ator estruturador do campo simbólico, ganhando relevância no âmbito das conjunturas políticas. Dessa forma, os resultados deste trabalho apontam para a disputa de sentidos instaurada na editoria de educação do jornal FSP. Porém, este tensionamento discursivo, longe de explicitar conflitos endógenos no posicionamento do jornal, expõe a tensão que existente na cena discursiva brasileira.

Além de melhor perceber o funcionamento da argumentação na mídia, este trabalho também procurou entender como a questão social, e, em particular, a demanda por educação pública, é representada na imprensa.

\section{Referências}

AMARAL, Márcia F. Lugares de fala: um conceito para abordar o segmento popular da grande imprensa. Contracampo, n. 12, p. 103-114, 2005. Disponível em: http://periodicos.uff.br/contracampo/issue/view/1004. Acesso em: 2 maio 2019.

\section{ANDRADE, Gislaine R. Expressões da questão social no contexto da escola} pública: olhares sobre a gestão escolar. 2017. 179f. Dissertação (Mestrado em Educação) - Programa de Pós- Graduação em Educação da Universidade do Vale do Rio dos Sinos, São Leopoldo, 2017.

BRANDÃO, Helena H. N. Introdução à análise do discurso. 2. ed. São Paulo: Unicamp, 2004.

BRASIL. Constituição da República Federativa do Brasil. 24. ed. São Paulo: Saraiva, 2000.

BRITO, Luciana. Escolas de luta: a disputa entre projetos educacionais nas escolas ocupadas em São Paulo. Movimento: revista de educação. Niterói, ano 4, n. 6, p. 306-328, jan-jun. 2017. Disponível em:

http://www.revistamovimento.uff.br/index.php/revistamovimento/article/view/314. Acesso em: 3 maio 2019.

CAMPOS, Antônia. M.; MEDEIROS, Jonas; RIBEIRO, Márcio. M. Escolas de luta. São Paulo: Veneta, 2016.

CATINI, Carolina. R.; MELLO, Gustavo M. C. Escolas de luta, educação política.

Educação \& Sociedade, v. 37, n. 137, p. 1177-1202, 2016. Disponível em: http://www.scielo.br/pdf/es/v37n137/1678-4626-es-37-137-01177.pdf. Acesso em: 1 maio 2019.

CHAIA, Vera. Jornalismo e política: escândalos e relações de poder na câmara municipal de São Paulo. São Paulo: Hacker, 2004. 
CHARAUDEAU, Patrik. Discurso das mídias. São Paulo: Contexto, 2012.

EZEQUIEL, Vanderlei de C. A mercantilização das questões sociais e o

discurso da "ajuda". 2005. 208f. Dissertação (Mestrado em Comunicação) Faculdade Cásper Líbero, 2005. Disponível em: https://casperlibero.edu.br/wpcontent/uploads/2014/02/02-A-Mercantiliza\%C3\%A7\%C3\%A3o-das-

quest\%C3\%B5es-sociais-e-o-espet\%C3\%A1culo-da-ajuda.pdf. Acesso em: 1 maio 2019.

EZEQUIEL, Vanderlei de C. Questões sociais e discurso político eleitoral. In: CHAIA, Vera; COELHO, Cláudio; CARVALHO, Rodrigo (orgs.). Mídia e política: estudos sobre a democracia e os meios de comunicação no Brasil. São Paulo: Anita Garibaldi, 2015. p. 95-109.

FIORIN, José Luiz. O regime de 1964: discurso e ideologia. São Paulo: Atual, 1988.

GALELLI, Cíntia Y.; BEDÊ, Luiza. Embates ideológicos em torno da palavra "diálogo" durante a implementação da reorganização escolar de 2015. Caleidoscópio, v. 15, n. 2, p. 284-294, 2017. Disponível em:

http://revistas.unisinos.br/index.php/calidoscopio/article/view/cld.2017.152.06/617 5. Acesso em: 3 maio 2019.

INDURSKY, Freda. Argumentação na mídia: do fio do discurso ao processo discursivo - um contraponto. Espaços de circulação da linguagem, Santa Maria, n. 27, p. 55-66, jul./dez. 2003.

MAINGUENEAU, Dominique. Novas tendências em análise de discurso.

Campinas: Editora Unicamp/Pontes, 1989.

MAINGUENEAU, Dominique. Termos-chave da análise do discurso. Belo Horizonte: UFMG, 2000.

MELITO, Leandro. "O movimento secundarista é 100\% horizontal", defende aluno que ocupou colégio em SP. Empresa Brasil de comunicação. Disponível em: http://www.ebc.com.br/cidadania/2016/05/ocupacoes-nas-escolas-entenda-omovimento-estudantessecundaristas. Acesso em: 3 maio 2016.

MONTEIRO, André. SP vai transferir mais de um milhão de alunos para dividir escolas por séries. Folha de S. Paulo, São Paulo, 2015. Disponível em:

https://www1.folha.uol.com.br/fsp/cotidiano/233990-sp-vai-transferir-mais-de-1milhao-de-alunos-para-dividir-escolas-por-series.shtml. Acesso em: 3 set. 2016.

MOTTA, Luiz Gonzaga. Ideologia e processo de seleção de notícias. In: MOTTA, Luiz Gonzaga (org.). Imprensa e poder. Brasília: Unb/Imprensa Oficial do Estado, 2002.

NAVARRO, Cristiano; BRASILINO, Luís. Escolas de lua. Le monde diplomatique. Disponível em: https://diplomatique.org.br/escolas-de-luta/. Acesso em: 1 maio 2019.

ORLANDI, Eni Puccinelli. Do sujeito na história e no símbolo. Escritos n. 4. Campinas: publicação do Laboratório de Estudos Urbanos Nudecri/LABERURB, p. 17-27, maio, 1999. Disponível em:

https://www.labeurb.unicamp.br/portal/pages/pdf/escritos/Escritos4.pdf. Acesso em: 4 maio 2019. 
ORLANDI, Eni Puccinelli. Análise de discurso: princípios e procedimentos. 9. ed. Campinas: Pontes Editores, 2010.

PEREGRINO, Mônica D. Desigualdade numa escola em mudança: trajetórias e embates na escolarização pública de jovens pobres. Tese (Doutorado em Educação) - Faculdade de Educação, Universidade Federal Fluminense, Niterói, 2006.

Disponível em:

http://www.bdae.org.br/dspace/bitstream/123456789/703/1/tese.pdf. Acesso em: 1 maio 2019.

SILVA, Luiz Martins. Imprensa e cidadania: possibilidade e contradições. In:

MOTTA, Luiz Gonzaga (org.) Imprensa e poder. Brasília: Unb/Imprensa Oficial do Estado, 2002.

TELLES, Vera da Silva. Direitos sociais: afinal de que se trata? Belo Horizonte: UFMG, 2006.

VALLE, Maria R. O diálogo é a violência: movimento estudantil e ditadura militar no Brasil. Campinas: Unicamp, 2016.

YAZBEK, Maria C. Classes subalternas e assistência social. São Paulo: Cortez, 1993. 